\title{
Previous tonsillectomy modifies odds of tonsil and base of tongue cancer
}

\author{
Jose P Zevallos ${ }^{\star}, 1,2,3,5$, Angela L Mazul ${ }^{3,5}$, Nidia Rodriguez ${ }^{3}$, Mark C Weissler ${ }^{1}$, Paul Brennan ${ }^{4}$, \\ Devasena Anantharaman ${ }^{4}$, Behnoush Abedi-Ardekani ${ }^{4}, \mathrm{D}$ Neil Hayes ${ }^{2}$ and Andrew F Olshan ${ }^{2,3}$ \\ ${ }^{1}$ Department of Otolaryngology/Head and Neck Surgery, University of North Carolina at Chapel Hill School of Medicine, 170 \\ Manning Drive, CB 7070, Chapel Hill, NC 27599, USA; ${ }^{2}$ Lineberger Comprehensive Cancer Center, University of North Carolina at \\ Chapel Hill, Chapel Hill, NC, USA; ${ }^{3}$ Department of Epidemiology, Gillings School of Global Public Health, University of North \\ Carolina at Chapel Hill, Chapel Hill, NC, USA and ${ }^{4}$ International Agency for Research on Cancer (IARC), Lyon, France
}

Background: Tonsillectomy is a commonly performed surgical procedure that involves removal of the palatine tonsils. The purpose of this study is to examine the association between previous tonsillectomy and odds of oropharyngeal squamous cell carcinoma (OPSCC) in a large population-based case-control study. We hypothesise that previous tonsillectomy is associated with a decreased odds of tonsil cancer with no impact on the odds of developing base of tongue (BOT) cancer.

Methods: This was a population-based, frequency-matched case-control study with multinomial logistic regression, including 1378 controls, 108 BOT cancer cases, and 198 tonsil cancer cases. Demographic and risk factor data were collected using a structured questionnaire during an in-home visit conducted by trained nurse-interviewers. The human papillomavirus (HPV) tumour status was determined through Luminex-based multiplex PCR and p16 status by immunohistochemistry.

Results: Previous tonsillectomy was associated with a nearly two-fold increased odds of $\mathrm{BOT}$ cancer $(\mathrm{OR}=1.95,95 \% \mathrm{Cl} 1.25-3.06$, $P=0.003)$ and a large decrease in the odds of tonsil cancer $(\mathrm{OR}=0.22,95 \% \mathrm{Cl} 0.13-0.36, P<0.001)$. When HPV status was considered, tonsillectomy was associated with a decreased odds of HPV-positive tonsil cancer $(\mathrm{OR}=0.17,95 \% \mathrm{Cl} 0.08-0.34$, $P<0.001)$ and an increased risk of HPV-positive BOT cancer (OR=2.46, 95\% Cl 1.22-4.95, $P=0.012)$. When p16 status was considered, tonsillectomy was associated with an increased odds of p16-positive BOT cancer $(\mathrm{OR}=2.24,95 \% \mathrm{Cl} 1.16-4.35$, $P=0.017)$ and a decreased odds of p16-positive tonsil cancer $(\mathrm{OR}=0.14,95 \% \mathrm{Cl} 0.07-0.31, P<0.001)$.

Conclusions: Previous tonsillectomy modifies the odds of both tonsil and BOT cancer, with decreased odds of tonsil cancer and increased odds of BOT cancer. A history of previous tonsillectomy may play a role in OPSCC risk stratification when considered along with other covariates such as sexual history, smoking status, and age.

Oropharyngeal squamous cell carcinoma (OPSCC) is an increasingly common cancer of the upper aerodigestive tract, and includes cancers arising from the tonsils, base of tongue (BOT), soft palate, and lateral and posterior pharyngeal walls. Although traditionally associated with heavy tobacco and alcohol consumption, it is estimated that $\sim 60-70 \%$ of incident OPSCC cases are attributable to human papillomavirus (HPV) (D'Souza et al, 2007; Ang et al, 2010; Chaturvedi et al, 2011). A rise in HPV-positive OPSCC has occurred since the 1980s in the United States that has been attributed to changing sexual practices beginning in the $1960 \mathrm{~s}$ (Ernster et al, 2007; Chaturvedi et al, 2013). The HPV epidemic has changed the demographic characteristics of OPSCC patients considerably. Patients with HPV-positive OPSCC are generally younger than those with HPV-negative OPSCC and are often never smokers. An association with increased number of sexual partners and earlier sexual debut has also been demonstrated

\footnotetext{
*Correspondence: Dr JP Zevallos; E-mail: jose_zevallos@med.unc.edu

${ }^{5}$ These authors contributed equally to this work.
}

Received 14 October 2015; revised 29 January 2016; accepted 14 February 2016; published online 15 March 2016

(c) 2016 Cancer Research UK. All rights reserved 0007-0920/16 
(D’Souza et al, 2009; Heck et al, 2010). The HPV-positive OPSCC is an increasingly significant public health problem; it is projected that by $2020 \mathrm{HPV}$-positive OPSCC will overtake cervical cancer as the most common HPV-related malignancy in the United States (Chaturvedi et al, 2011).

Tonsillectomy is a commonly performed surgical procedure that involves removal of the palatine tonsils, most often in children for hypertrophic tonsils, chronic infection, or obstructive sleep apnoea (Derkay, 1993). The rates of tonsillectomy in the United States have changed significantly over the past several decades. Rosenfeld and Green (1990) and others (Derkay, 1993; Erickson et al, 2009) demonstrated a sharp decline in tonsillectomy rates beginning in the late 1970s. It is well established that an increase in HPV-related OPSCC began to increase in the 1990s (Chaturvedi et al, 2008, 2011, 2013). The association between tonsillectomy and risk of OPSCC has not been extensively investigated. A recent study of the Danish Cancer Registry suggests a reduction in risk of tonsil cancer in patients with a previous history of tonsillectomy (Fakhry et al, 2015). The purpose of this study is to examine the association between previous tonsillectomy and risk of OPSCC using a large North Carolina population-based head and neck cancer case-control study. We hypothesise that previous tonsillectomy is associated with a decreased risk of tonsil cancer with no impact on the risk of BOT cancer.

\section{MATERIALS AND METHODS}

Study population. The Carolina Head and Neck Cancer Study (CHANCE) is a population-based case-control study of squamous cell carcinoma of the head and neck (Divaris et al, 2010). Case ascertainment utilised rapid ascertainment of newly diagnosed cancer cases through the North Carolina Central Cancer Registry. Cases were diagnosed with primary squamous cell carcinoma of the oral cavity, pharynx, and larynx between 1 January 2002 and 28 February 2006, were aged 20 to 80 years at diagnosis, and resided in a 46-county region in central North Carolina. Benign tumours, carcinomas in situ, papillary carcinomas, and adenocarcinomas were excluded. Controls were identified through the North Carolina Department of Motor Vehicle records and were frequency matched with cases on age, race, and sex.

The Carolina Head and Neck Cancer Study enrolled 1368 total cases; however, as we are only interested in OPSCC, we restricted the tumour site to only the oropharynx $(N=372)$. Race other than European American and African American were excluded from the analysis because of sparse numbers $(N=11)$. As we are interested specifically in the OPSCC subsites, cases were classified into two categories: (1) BOT: C01.9 and C02.4 and (2) tonsil: C09.0, C09.1, C09.8, and C09.9. We excluded OPSCC of the vallecular (C10.0; $N=10)$, soft palate (C05.1, C05.2; $N=23)$, and unspecified subsites (C10.8 and $\mathrm{C} 10.9 ; N=23)$ because of small sample size. The HPV typing and p16 immunohistochemistry was performed on all cases of oropharyngeal tumours for which tumour blocks were available $(N=213)$. All European-American and AfricanAmerican controls were included in the analysis $(N=1378)$. This study was approved by the institutional review board at the University of North Carolina at Chapel Hill.

Questionnaire and clinical assessment. Demographic, lifestyle, oral health, diet, and other risk factor information were collected using a structured questionnaire during an in-home visit conducted by trained nurse-interviewers. The median time between diagnosis and in-home interview was 4 months (interquartile range: 3-6 months). Two questions addressed a history of previous tonsillectomy, including, 'Were your tonsils removed?' and 'How old were you when tonsils removed?' For subjects who were unable to recall the exact age of tonsillectomy, the subject was able to answer child, teenager, or adult. Age at tonsillectomy was defined as before 13 years of age (child) and after 13 years of age (teenager and adult). The CHANCE questionnaire focussed on lifestyle and medical and family history risk factors. Interviewers did not collect information on tonsillectomy performed as part of the diagnostic workup or OPSCC therapy. Confounders to be adjusted for in statistical models were selected a priori based on their potential association with risk of OPSCC and tonsillectomy. Confounders obtained from the questionnaire included: age race, sex, smoking ( $<10$ pack-years and $\geqslant 10$ pack-years), insurance status (private, Medicare/Medicaid, none, and other), education (some high school, completed high school, some college and above), alcohol (1 drink or less per week/ $>1$ drink a week), and number of sexual partners $(0-1,2-5,6-14$, and $14+)$.

p16 immunohistochemistry and HPV typing. Immunohistochemistry (IHC) for p16 was performed according to the protocol provided with the CINtec Histology p16 ${ }^{\text {INK4a }}$ Kit (Ref 9511, mtm laboratories, Heidelberg, Germany) for the qualitative detection of the p16 antigen on slides prepared from formalin-fixed, paraffinembedded biopsies. The p16 IHC scoring method used in this study was developed based on the methodology by Koo et al (2009), where expression was scored based on the percentage $(0 \%=0,1-10 \%=1,11-50 \%=2,51-80 \%=3$, and $81-100 \%=4)$ and intensity (none $=0$, weak $=1$, moderate $=2$, and strong $=3$ ) of nuclear or cytoplasmic staining, and a combined score of $\geqslant 4$ was considered positive for $\mathrm{p} 16$ overexpression. This algorithm has been previously published in a study from the International Agency for Research on Cancer (IARC) (Anantharaman et al, 2013), and has been compared with other p16 scoring methods with similar results (Weinberger et al, 2006; Smeets et al, 2007; Singhi and Westra, 2010). The HPV typing was determined through DNA extraction and genotyping by Luminex-based multiplex PCR (TS-E7-MPG, IARC, Lyon, France) (Gheit et al, 2006; Schmitt et al, 2006, 2010). Tumours were classified as HPVpositive if they were positive for HPV16 or HPV18.

Statistical analysis. Differences in descriptive statistics by OPSCC subsite were estimated using the $\chi^{2}$ test and Fisher's exact test when cells were sparse. Unconditional logistic regression was used to calculate odds ratio (OR) adjusted with the confounders and matching factors: age, race, and gender. Subsite-specific adjusted ORs were calculated with unconditional multinomial logistic regression. To further explore the role of HPV, conditional logistic regression was used to calculate HPV/p16 status and subsite stratified ORs based on the matching factors, including age (defined in 7 categories), race (White/Black), and sex. All statistical analyses were implemented using SAS 9.3 (SAS Institute, Cary, NC, USA).

\section{RESULTS}

The study population comprised 1378 controls and 361 OPSCC cases, including 108 BOT and 198 tonsil cancer cases. Table 1 shows the demographic, risk factor, and tumour characteristics of the controls and cases by subsite. Cases and controls differed with respect to sex, age, tobacco pack-years, education level, insurance status, age at tonsillectomy, and rates of previous tonsillectomy (40\% vs $26.3 \%$ in controls and cases, respectively, $P<0.001$ ). Among study subjects with a history of tonsillectomy, 2 (2.5\%) cases and $6(1.1 \%)$ controls underwent the procedure within 10 years of enrolment in the study. No significant differences were noted between BOT and tonsil cancer cases with respect to age, sex, race, education and insurance status, p16 tumour status, and HPV tumour status. A history of previous tonsillectomy differed significant between tonsil (11.3\%) and BOT (53.3\%) cancer cases $(P<0.0001)$. The BOT cancer cases with a history of tonsillectomy 
Table 1. Descriptive statistics and comparisons between controls and all oropharynx cases and comparisons by subsite

\begin{tabular}{|c|c|c|c|c|c|c|}
\hline & $\begin{array}{c}\text { Control } \\
(N=1378) \\
N(\%)\end{array}$ & $\begin{array}{l}\text { All oropharynx } \\
\begin{array}{c}(N=361) \\
N(\%)\end{array}\end{array}$ & $P$-value & $\begin{array}{l}\text { Base of tongue } \\
\begin{array}{c}(N=108) \\
N(\%)\end{array}\end{array}$ & $\begin{array}{c}\text { Tonsil } \\
(N=198) \\
N(\%)\end{array}$ & $P$-value \\
\hline \multicolumn{7}{|l|}{ Tonsillectomy } \\
\hline & $544(40 \%)$ & 93 (26.3\%) & \multirow{2}{*}{$<0.001$} & $56(53.3 \%)$ & $22(11.3 \%)$ & \multirow{2}{*}{$<0.001$} \\
\hline Missing & 19 & 8 & & 3 & 3 & \\
\hline \multicolumn{7}{|l|}{ Race } \\
\hline \multicolumn{7}{|l|}{ Education } \\
\hline Some High School & $217(15.7 \%)$ & $98(27.1 \%)$ & \multirow[t]{3}{*}{$<0.001$} & $22(20.4 \%)$ & $55(27.8 \%)$ & \multirow[t]{3}{*}{0.192} \\
\hline Completed High School & $332(24.1 \%)$ & $97(26.9 \%)$ & & $28(25.9 \%)$ & $57(28.8 \%)$ & \\
\hline Some College and above & $829(60.2 \%)$ & $166(46 \%)$ & & $58(53.7 \%)$ & $86(43.4 \%)$ & \\
\hline \multicolumn{7}{|l|}{ Tobacco pack-years } \\
\hline Male & 960 (69.7\%) & $299(82.8 \%)$ & \multirow[t]{2}{*}{$<0.001$} & 95 (88\%) & 165 (83.3\%) & \multirow[t]{2}{*}{0.279} \\
\hline Female & 418 (30.3\%) & 62 (17.2\%) & & $13(12 \%)$ & 33 (16.7\%) & \\
\hline \multicolumn{7}{|l|}{ Insurance } \\
\hline Private & $556(40.4 \%)$ & $181(50.3 \%)$ & \multirow[t]{5}{*}{$<0.001$} & $59(54.6 \%)$ & $104(52.5 \%)$ & \multirow[t]{5}{*}{0.980} \\
\hline Medicaid/Medicare & 437 (31.7\%) & $93(25.8 \%)$ & & $24(22.2 \%)$ & 44 (22.2\%) & \\
\hline None & 76 (5.5\%) & 40 (11.1\%) & & $11(10.2 \%)$ & $22(11.1 \%)$ & \\
\hline Other & $308(22.4 \%)$ & $46(12.8 \%)$ & & $14(13 \%)$ & $28(14.1 \%)$ & \\
\hline Missing & 1 & 1 & & & & \\
\hline \multicolumn{7}{|l|}{ Tumour p16 status } \\
\hline Positive & - & $84(34.0 \%)$ & \multirow[t]{3}{*}{-} & $46(65.7 \%)$ & 99 (69.2\%) & \multirow[t]{3}{*}{0.6051} \\
\hline Negative & - & $163(66.0 \%)$ & & $24(34.3 \%)$ & $44(30.8 \%)$ & \\
\hline Missing & 1378 & 125 & & 38 & 55 & \\
\hline 60-64 Years & 205 (14.9\%) & $53(14.7 \%)$ & & $17(15.7 \%)$ & $22(11.1 \%)$ & \\
\hline 65-69 Years & 247 (17.9\%) & 35 (9.7\%) & & $10(9.3 \%)$ & $18(9.1 \%)$ & \\
\hline 70-74 Years & $231(16.8 \%)$ & $25(6.9 \%)$ & & $10(9.3 \%)$ & $10(5.1 \%)$ & \\
\hline$>75$ Years & $171(12.4 \%)$ & 9 (2.5\%) & & $3(2.8 \%)$ & $4(2 \%)$ & \\
\hline Age at tonsillectomy & & & & & & \\
\hline Child & $417(77.1 \%)$ & $76(82.6 \%)$ & $<0.001$ & $52(92.9 \%)$ & $15(68.2 \%)$ & $<0.001$ \\
\hline Teenager & $37(6.8 \%)$ & $5(5.4 \%)$ & & $1(1.8 \%)$ & 3 (13.6\%) & \\
\hline Adult & 87 (16.1\%) & 11 (12.0\%) & & $3(5.4 \%)$ & $4(18.2 \%)$ & \\
\hline No tonsillectomy & 815 & 260 & & 49 & 173 & \\
\hline Missing & 22 & 9 & & 3 & 3 & \\
\hline
\end{tabular}

were significantly more likely to have undergone the procedure in childhood (92.9\% among BOT cases and 68.2\% among tonsil cancer cases, $P<0.001)$.

Table 2 presents the results of the logistic regression model for selected factors and the odds of OPSCC by subsite. A greater number of sexual partners and $>10$ pack-year tobacco history were associated with an increased odds of all OPSCC, tonsil, and BOT cancers compared with controls. When all OPSCC cases were evaluated, there was a significantly decreased odds of cancer associated with previous tonsillectomy $(\mathrm{OR}=0.63,95 \%$ confidence interval (CI) $0.47-0.85, P=0.003)$. When OPSCC subsite was considered, previous tonsillectomy was associated with a nearly two-fold increased odds of BOT cancer $(\mathrm{OR}=1.95,95 \%$ CI $1.25-3.06, P=0.003)$ and a large decrease in the odds of tonsil cancer $(\mathrm{OR}=0.22,95 \%$ CI $0.13-0.36, P<0.001)$. We found tonsillectomy not associated with sites of head and neck cancer not commonly associated with HPV (Supplementary Table S1). We then considered whether age at tonsillectomy affected the risk of OPSCC by subsite (Table 3). Childhood tonsillectomy (age $<13$ years) was strongly associated with increased odds of BOT cancer (adjusted $\mathrm{OR}=2.46,95 \%$ CI $1.55-3.92, \quad P<0.001$ ), and no association was noted with tonsillectomy after age 13 years (OR $=0.33$, 95\% CI $0.08-1.42, P=0.138)$. Tonsillectomy before age 13 years $(\mathrm{OR}=0.19,95 \% \mathrm{CI} 0.10-0.33, P<0.001)$ and after age 13 years $(\mathrm{OR}=0.32,95 \% \mathrm{CI} 0.14-01.00, P=0.017)$ was associated with a significantly decreased odds of tonsil cancer.

In an exploratory analysis including cases with available tumour tissue, we then examined the odds of tonsil and BOT cancer by 
Table 2. Adjusted odds ratio for all oropharyngeal cancer cases and by subsite compared with controls ${ }^{a}$

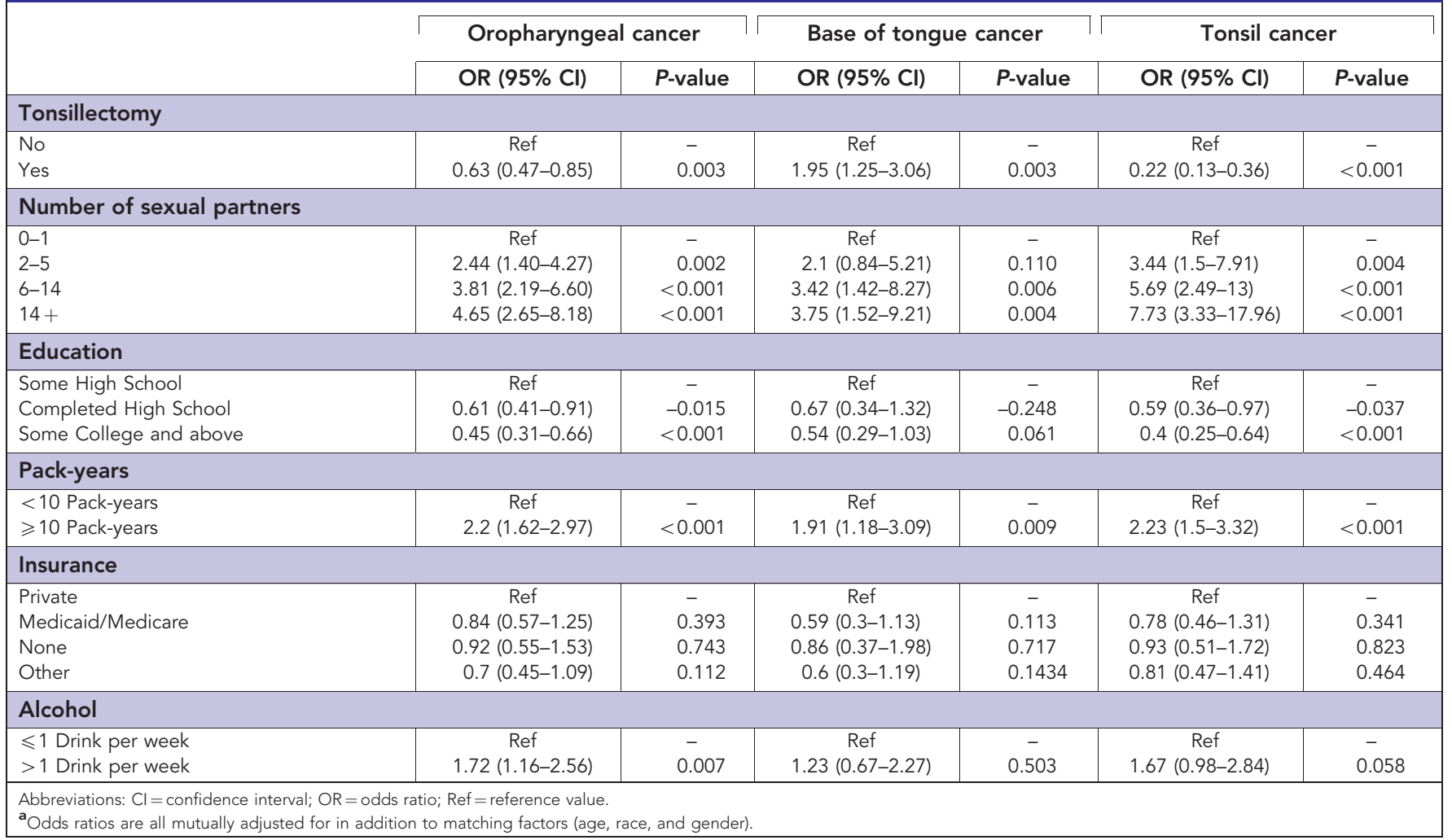

\section{Table 3. Adjusted odds ratios for age at tonsillectomy by oropharyngeal subsite compared with controls ${ }^{\mathrm{a}}$}

\begin{tabular}{|c|c|c|c|c|}
\hline & \multicolumn{2}{|c|}{ Base of tongue } & \multicolumn{2}{|c|}{ Tonsil } \\
\hline & OR $(95 \% \mathrm{Cl})$ & $P$-value & OR $(95 \% \mathrm{Cl})$ & $P$-value \\
\hline \multicolumn{5}{|l|}{ Age at tonsillectomy } \\
\hline $\begin{array}{l}\text { No tonsillectomy } \\
<13 \text { years } \\
\geqslant 13 \text { years }\end{array}$ & $\begin{array}{c}\text { Ref } \\
2.46(1.55-3.92) \\
0.33(0.08-1.42)\end{array}$ & $\begin{array}{c}- \\
<0.001 \\
0.138\end{array}$ & \begin{tabular}{l}
\multicolumn{1}{c}{ Ref } \\
$0.19(0.1-0.34)$ \\
$0.32(0.14-0.72)$
\end{tabular} & $\begin{array}{r}- \\
<0.001 \\
0.006\end{array}$ \\
\hline \multicolumn{5}{|c|}{ Number of sexual partners } \\
\hline $\begin{array}{l}0-1 \\
2-5 \\
6-14 \\
14+\end{array}$ & $\begin{array}{c}\text { Ref } \\
2.22(0.89-5.54) \\
3.5(1.45-8.45) \\
3.96(1.61-9.73)\end{array}$ & $\begin{array}{l}- \\
0.087 \\
0.005 \\
0.003\end{array}$ & $\begin{array}{c}\text { Ref } \\
3.46(1.5-7.95) \\
5.71(2.5-13.05) \\
7.8(3.36-18.15)\end{array}$ & $\begin{aligned} & - \\
& 0.004 \\
< & 0.001 \\
< & 0.001\end{aligned}$ \\
\hline \multicolumn{5}{|l|}{ Education } \\
\hline $\begin{array}{l}\text { Some High School } \\
\text { Completed High School } \\
\text { Some College and above }\end{array}$ & $\begin{array}{c}\text { Ref } \\
0.66(0.34-1.31) \\
0.5(0.26-0.94)\end{array}$ & $\begin{array}{c}- \\
0.234 \\
0.031\end{array}$ & $\begin{array}{c}\text { Ref } \\
0.59(0.36-0.96) \\
0.4(0.25-0.64)\end{array}$ & $\begin{array}{r}- \\
0.034 \\
<0.001\end{array}$ \\
\hline \multicolumn{5}{|l|}{ Pack-years } \\
\hline $\begin{array}{l}<10 \text { Pack-years } \\
\geqslant 10 \text { Pack-years }\end{array}$ & $\begin{array}{c}\text { Ref } \\
1.88(1.16-3.04)\end{array}$ & - & $\begin{array}{c}\text { Ref } \\
1.66(0.98-2.83)\end{array}$ & - \\
\hline \multicolumn{5}{|l|}{ Insurance } \\
\hline $\begin{array}{l}\text { Private } \\
\text { Medicaid/Medicare } \\
\text { None } \\
\text { Other }\end{array}$ & $\begin{array}{l}\text { Ref } \\
0.59(0.31-1.15) \\
0.81(0.35-1.87) \\
0.59(0.3-1.18)\end{array}$ & $\begin{array}{l}- \\
0.120 \\
0.624 \\
0.138\end{array}$ & \begin{tabular}{l}
\multicolumn{1}{c}{ Ref } \\
$0.78(0.47-1.32)$ \\
$0.92(0.5-1.7)$ \\
$0.81(0.47-1.41)$
\end{tabular} & $\begin{array}{l}- \\
0.360 \\
0.797 \\
0.457\end{array}$ \\
\hline \multicolumn{5}{|l|}{ Alcohol } \\
\hline $\begin{array}{l}\leqslant 1 \text { drink per week } \\
>1 \text { drink per week }\end{array}$ & $\begin{array}{c}\text { Ref } \\
1.30(0.7-2.39)\end{array}$ & - & $\begin{array}{c}\text { Ref } \\
2.24(1.51-3.32)\end{array}$ & $<0.001$ \\
\hline
\end{tabular}

HPV and by p16 status (Table 4). Tonsillectomy was associated with a decreased odds of HPV-positive tonsil cancer $(\mathrm{OR}=0.17$, $95 \%$ CI $0.08-0.34, P<0.001)$ and a decreased but imprecise odds of
HPV-negative tonsil cancer $(\mathrm{OR}=0.66,95 \%$ CI $0.24-1.81$, $P=0.415)$. Conversely, tonsillectomy was associated with an increased odds of HPV-positive BOT cancer $(\mathrm{OR}=2.46,95 \% \mathrm{CI}$ 
Table 4. Adjusted odds ratio for tonsillectomy and oropharyngeal subsite and HPV/p16 status compared with controls ${ }^{\mathrm{a}}$

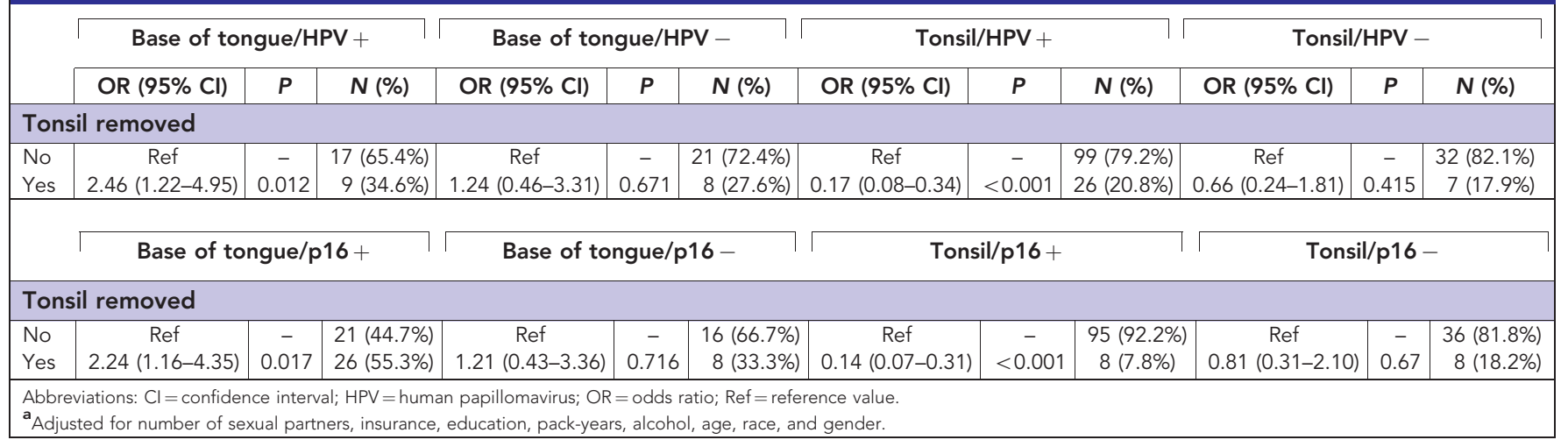

$1.22-4.95, P=0.012)$ and a weak and imprecise increase in odds of HPV-negative BOT cancer $(\mathrm{OR}=1.24,95 \% \mathrm{CI} 0.46-3.31, P=0.671)$. Tonsillectomy was also associated with a significantly increased odds of p16-positive BOT cancer (OR $=2.24,95 \%$ CI $1.16-4.35, P=0.017$ ) and only a weak increase in odds of p16-negative BOT cancer $(\mathrm{OR}=1.21,95 \%$ CI $0.43-3.36, \quad P=0.716)$. Tonsillectomy was associated with decreased odds of p16-positive tonsil cancer $(\mathrm{OR}=0.14,95 \%$ CI $0.07-0.31, P<0.001)$. A decrease of p16-negative tonsil cancer was also seen, but the $\mathrm{OR}$ had a very wide $\mathrm{CI}$ $(\mathrm{OR}=0.81,95 \% \mathrm{CI} 0.31-2.10, P=0.670)$. Finally, similar results were noted between previous tonsillectomy, $\mathrm{HPV}+/ \mathrm{p} 16+$ BOT cancer $(\mathrm{OR}=2.18,95 \% \mathrm{CI} 1.1-4.4)$, and $\mathrm{HPV}+/ \mathrm{p} 16+$ tonsil cancer $(\mathrm{OR}=0.16,95 \%$ CI $0.08-0.37)$.

\section{DISCUSSION}

This population-based case-control study explores the association between previous tonsillectomy and odds of OPSCC. We found that previous tonsillectomy was associated with a significantly decreased odds of OPSCC overall that was driven by a sharp and expected decrease in tonsil cancer specifically. These data suggest that tonsillectomy results in a reduction of oropharyngeal lymphoid tissue susceptible to malignant transformation (Fakhry et al, 2015). An unexpected finding from this analysis was the positive association between odds of BOT cancer and previous tonsillectomy. Although having a tonsillectomy is inversely associated with odds of tonsil cancer, our data suggest that tonsillectomy may be associated with an increased odds of BOT cancer. One possible explanation is lingual tonsillar hypertrophy in patients with a history of tonsillectomy, resulting in increased lymphoid tissue in the BOT. Enlargement of the lingual tonsils has been noted in up to one-third of paediatric patients undergoing adenotonsillectomy (Fricke et al, 2006), and is a recognised cause of persistent sleep apnoea and airway obstruction in this population (Jesberg, 1956; Golding-Wood and Whittet, 1989; Cohle et al, 1993; Jones and Cohle, 1993; Breitmeier et al, 2005; Abdel-Aziz et al, 2011; Friedman et al, 2015). Our data suggest that the odds of BOT cancer is strongly increased in patients undergoing tonsillectomy as children (age $<13$ years) compared with adolescents and adults (age $>13$ years). The difference in odds of BOT cancer by age of tonsillectomy further supports the possible association between lingual tonsillar hypertrophy and increased susceptibility to BOT cancer. The most common indication for tonsillectomy in children is obstruction secondary to adenotonsillar hypertrophy (Smith and Pereira, 2007; Macfarlane et al, 2008). In contrast, the most common indication for tonsillectomy in adults is chronic or recurrent tonsillitis (Hoddeson and Gourin, 2009).
An exploratory analysis of the association between tonsillectomy, tonsil, and BOT cancer, and HPV status yielded interesting results. When both subsite and HPV status were considered, we demonstrated that tonsillectomy was associated with a significantly decreased odds of HPV-positive tonsil cancer and a decreased but insignificant odds of HPV-negative tonsil cancer. The weaker association between tonsillectomy and HPV-negative tonsil cancer may result from susceptibility of nonlymphoid tissues of the tonsillar region (anterior tonsillar pillars, posterior tonsillar pillars, and tonsillar fossa) to HPV-negative, tobacco-associated cancer even in the setting of previous tonsillectomy. Ultimately, the decrease in odds of tonsil cancer in patients with a history of tonsillectomy is expected and logical. The association by HPV status should be explored further in larger studies. With respect of HPV-positive and HPV-negative BOT cancer, our data suggest that the association between tonsillectomy and an increased odds of BOT cancer is strongest for HPV-positive tumours. The reason for this difference by HPV status remains unclear and warrants further investigation, and may reflect a relatively small sample size of HPV-negative tumours.

Recently, the possibility of prophylactic tonsillectomy as a method of secondary OPSCC prevention has been considered (Chaturvedi, 2015; Fakhry et al, 2015). Although we demonstrate a reduction in overall risk of OPSCC cancer associated with tonsillectomy, our study was not designed to address this question. It is important to consider that despite being a commonly performed surgery, the morbidity of tonsillectomy is not insignificant (Randall and Hoffer, 1998; Windfuhr et al, 2008, 2009). Furthermore, as demonstrated by Fakhry et al (2015), the relative rarity of OPSCC further precludes tonsillectomy from being an effective method of prevention. Vaccination against high-risk HPV types has the potential to serve as a safer and more effective method of primary prevention of OPSCC than tonsillectomy (D'Souza and Dempsey, 2011). Nonetheless, when considered along with other covariates such as sexual history, smoking status, and age, a history of tonsillectomy may play a role in risk stratification (Chaturvedi, 2015; Fakhry et al, 2015).

This study has several limitations, many of which are inherent to the case-control study design. The use of self-reported tonsillectomy questionnaire data presents the possibility of recall bias and differential misclassification by disease status. However, recall of tonsillectomy would be very long for both the cases and the controls and at the time of recruitment. Because most tonsillectomies among cases and controls occurred at a very young age, medical record abstract is not feasible. Two previous studies have examined the accuracy of tonsillectomy recall, demonstrating sensitivity and specificity of recall were $92.7 \%$ and $77.5 \%$ in one study and $78.9 \%$ and $80.1 \%$ in the other, respectively (Krall et al, 1988; Linet et al, 1989). Using the false discovery and false omission rates from these studies, we conducted a sensitivity 
analysis (methods in Supplementary Material) and found that our estimates for tonsillectomy and tonsil cancer are very stable to changes in recall (Supplementary Table S2). However, for BOT cancer as differential recall between cases and controls widens, the estimates move closer to null and eventually crosses the null (Supplementary Table S1). It is unlikely that recall was that dramatically different between the cases and the controls. Another important limitation of this study is that tumour tissue was not available for all OPSCC samples in this cohort, limiting our analysis including HPV to a secondary, exploratory analysis. Tonsil cancer samples were more likely to be typed and this could potentially lead to selection bias affecting our analysis by HPV and p16 status. However, subjects with available HPV status and those without were similar with respect to demographics, age, smoking history, number of sexual partners, and stage at presentation, suggesting that HPV status would be similar between those typed and nontyped. Possible selection bias would not affect our overall results with respect to risk of tonsil vs BOT cancer, or our results incorporating age at tonsillectomy, as all cases were included in these analyses. Furthermore, our results involving HPV and p16 typing were stratified by subsite, thus diminishing the potential impact of any selection bias. A final limitation of this study is that some of the comparisons were based on small numbers and ORs were associated with wide CIs. Despite these limitations, this study offers important insight into the association between previous tonsillectomy and risk of OPSCC.

The major strengths of this study include a relatively large number of diverse patients and a population-based, case-control study design. The availability of detailed smoking, HPV tumour status, sexual history, socioeconomic status, and other demographic covariates, as well as a frequency-matched control group, add to the validity of our findings. Data on age of tonsillectomy allowed us to demonstrate that the majority of cases and controls underwent tonsillectomy as children and presumably for reasons other than suspected oropharyngeal cancer. A very small fraction of cases and controls underwent tonsillectomy within 10 years of OPSCC diagnosis or enrolment in CHANCE, respectively. When a sensitivity analysis was conducted excluding subjects with a history of tonsillectomy within 10 years of enrolment in CHANCE, there were no significant differences in the study findings.

In conclusion, this population-based case-control study demonstrates that previous tonsillectomy is associated with a decreased odds of tonsil cancer and an increased odds of BOT cancer. Although these finding do not necessarily support the role of tonsillectomy as primary prevention, tonsillectomy should be considered when evaluating risk for OPSCC.

\section{ACKNOWLEDGEMENTS}

This study was supported in part by the National Cancer Institute (R01-CA90731) and the Lineberger Cancer Control Education Program (R25 CA57726).

\section{CONFLICT OF INTEREST}

The authors declare no conflict of interest.

\section{REFERENCES}

Abdel-Aziz M, Ibrahim N, Ahmed A, El-Hamamsy M, Abdel-Khalik MI, El-Hoshy H (2011) Lingual tonsils hypertrophy; a cause of obstructive sleep apnea in children after adenotonsillectomy: operative problems and management. Int J Pediatr Otorhinolaryngol 75: 1127-1131.
Anantharaman D, Gheit T, Waterboer T, Abedi-Ardekani B, Carreira C, Mckay-Chopin S, Gaborieau V, Marron M, Lagiou P, Ahrens W, Holcatova I, Merletti F, Kjaerheim K, Talamini R, Simonato L, Castellsague X, Macfarlane TV, Biggs AM, Thakker N, Znaor A, Thomson P, Canova C, Conway DI, Healy CM, Tommasino M, Pawlita M, Brennan P (2013) Human papillomavirus infections and upper aero-digestive tract cancers: the ARCAGE study. J Natl Cancer Inst 105: 536-545.

Ang KK, Harris J, Wheeler R, Weber R, Rosenthal DI, Nguyen-Tan PF, Westra WH, Chung CH, Jordan RC, Lu C, Kim H, Axelrod R, Silverman CC, Redmond KP, Gillison ML (2010) Human papillomavirus and survival of patients with oropharyngeal cancer. $N$ Engl J Med 363: 24-35.

Breitmeier D, Wilke N, Schulz Y, Albrecht K, Wenzel V, Kleemann WJ, Panning B, Troger HD (2005) The lingual tonsillar hyperplasia in relation to unanticipated difficult intubation: is there any relationship between lingual tonsillar hyperplasia and tonsillectomy? Am J Forensic Med Pathol 26: 131-135.

Chaturvedi AK (2015) Tonsillectomy and risk of oropharyngeal cancer: implications for research and prevention. Cancer Prev Res (Phila) 8(7): 577-579.

Chaturvedi AK, Anderson WF, Lortet-Tieulent J, Curado MP, FERLAY J, Franceschi S, Rosenberg PS, Bray F, Gillison ML (2013) Worldwide trends in incidence rates for oral cavity and oropharyngeal cancers. J Clin Oncol 31: $4550-4559$.

Chaturvedi AK, Engels EA, Anderson WF, Gillison ML (2008) Incidence trends for human papillomavirus-related and -unrelated oral squamous cell carcinomas in the United States. J Clin Oncol 26: 612-619.

Chaturvedi AK, Engels EA, Pfeiffer RM, Hernandez BY, Xiao W, Kim E, Jiang B, Goodman MT, Sibug-Saber M, Cozen W, Liu L, Lynch CF, Wentzensen N, Jordan RC, Altekruse S, Anderson WF, Rosenberg PS, Gillison ML (2011) Human papillomavirus and rising oropharyngeal cancer incidence in the United States. J Clin Oncol 29: 4294-4301.

Cohle SD, Jones DH, Puri S (1993) Lingual tonsillar hypertrophy causing failed intubation and cerebral anoxia. Am J Forensic Med Pathol 14: 158-161.

D'Souza G, Agrawal Y, Halpern J, Bodison S, Gillison ML (2009) Oral sexual behaviors associated with prevalent oral human papillomavirus infection. J Infect Dis 199: 1263-1269.

D'Souza G, Dempsey A (2011) The role of HPV in head and neck cancer and review of the HPV vaccine. Prev Med 53(Suppl 1): S5-S11.

D'Souza G, Kreimer AR, Viscidi R, Pawlita M, Fakhry C, Koch WM, Westra WH, Gillison ML (2007) Case-control study of human papillomavirus and oropharyngeal cancer. N Engl J Med 356: 1944-1956.

Derkay CS (1993) Pediatric otolaryngology procedures in the United States: 1977-1987. Int J Pediatr Otorhinolaryngol 25: 1-12.

Divaris K, Olshan AF, Smith J, Bell ME, Weissler MC, Funkhouser WK, Bradshaw PT (2010) Oral health and risk for head and neck squamous cell carcinoma: the Carolina Head and Neck Cancer Study. Cancer Causes Control 21: $567-575$.

Erickson BK, Larson St DR, Sauver JL, Meverden RA, Orvidas LJ (2009) Changes in incidence and indications of tonsillectomy and adenotonsillectomy, 1970-2005. Otolaryngol Head Neck Surg 140: 894-901.

Ernster JA, Sciotto CG, O'Brien MM, Finch JL, Robinson LJ, Willson T, Mathews M (2007) Rising incidence of oropharyngeal cancer and the role of oncogenic human papilloma virus. Laryngoscope 117: 2115-2128.

Fakhry C, Andersen KK, Christensen J, Agrawal N, Eisele DW (2015) The impact of tonsillectomy upon the risk of oropharyngeal carcinoma diagnosis and prognosis in the Danish Cancer Registry. Cancer Prev Res (Phila) 8(7): 583-589.

Fricke BL, Donnelly LF, Shott SR, Kalra M, Poe SA, Chini BA, Amin RS (2006) Comparison of lingual tonsil size as depicted on MR imaging between children with obstructive sleep apnea despite previous tonsillectomy and adenoidectomy and normal controls. Pediatr Radiol 36: 518-523.

Friedman NR, Prager JD, Ruiz AG, Kezirian EJ (2015) A pediatric grading scale for lingual tonsil hypertrophy. Otolaryngol Head Neck Surg 154(1): 171-174.

Gheit T, Landi S, Gemignani F, Snijders PJ, Vaccarella S, Franceschi S, Canzian F, Tommasino M (2006) Development of a sensitive and specific assay combining multiplex PCR and DNA microarray primer extension to detect high-risk mucosal human papillomavirus types. J Clin Microbiol 44(6): 2025-2031.

Golding-Wood DG, Whittet HB (1989) The lingual tonsil. A neglected symptomatic structure? J Laryngol Otol 103: 922-925. 
Heck JE, Berthiller J, Vaccarella S, Winn DM, Smith EM, Shan'gina O, Schwartz SM, Purdue MP, Pilarska A, Eluf-Neto J, Menezes A, Mcclean MD, Matos E, Koifman S, Kelsey KT, Herrero R, Hayes RB, Franceschi S, Wunsch-Filho V, Fernandez L, Daudt AW, Curado MP, Chen C, Castellsague X, FERRO G, Brennan P, Boffetta P, Hashibe M (2010) Sexual behaviours and the risk of head and neck cancers: a pooled analysis in the International Head and Neck Cancer Epidemiology (INHANCE) consortium. Int J Epidemiol 39: 166-181.

Hoddeson EK, Gourin CG (2009) Adult tonsillectomy: current indications and outcomes. Otolaryngol Head Neck Surg 140: 19-22.

Jesberg N (1956) Chronic, hypertrophic, lingual tonsillitis. AMA Arch Otolaryngol 64: 3-13.

Jones DH, Cohle SD (1993) Unanticipated difficult airway secondary to lingual tonsillar hyperplasia. Anesth Analg 77: 1285-1288.

Koo CL, Kok LF, Lee MY, Wu TS, Cheng YW, Hsu JD, Ruan A, Chao KC, Han CP (2009) Scoring mechanisms of p16INK4a immunohistochemistry based on either independent nucleic stain or mixed cytoplasmic with nucleic expression can significantly signal to distinguish between endocervical and endometrial adenocarcinomas in a tissue microarray study. J Transl Med 7: 25.

Krall EA, Valadian I, Dwyer JT, Gardner J (1988) Recall of childhood illnesses. J Clin Epidemiol 41: 1059-1064.

Linet MS, Harlow SD, Mclaughlin JK, Mccaffrey LD (1989) A comparison of interview data and medical records for previous medical conditions and surgery. J Clin Epidemiol 42: 1207-1213.

Macfarlane PL, Nasser S, Coman WB, Kiss G, Harris PK, Carney AS (2008) Tonsillectomy in Australia: an audit of surgical technique and postoperative care. Otolaryngol Head Neck Surg 139: 109-114.

Randall DA, Hoffer ME (1998) Complications of tonsillectomy and adenoidectomy. Otolaryngol Head Neck Surg 118: 61-68.

Rosenfeld RM, Green RP (1990) Tonsillectomy and adenoidectomy: changing trends. Ann Otol Rhinol Laryngol 99: 187-191.
Schmitt M, Bravo IG, Snijders PJ, Gissmann L, Pawlita M, Waterboer T (2006) Bead-based multiplex genotyping of human papillomaviruses. J Clin Microbiol 44: 504-512.

Schmitt M, Dondog B, Waterboer T, Pawlita M, Tommasino M, Gheit T (2010) Abundance of multiple high-risk human papillomavirus (HPV) infections found in cervical cells analyzed by use of an ultrasensitive HPV genotyping assay. J Clin Microbiol 48: 143-149.

Singhi AD, Westra WH (2010) Comparison of human papillomavirus in situ hybridization and p16 immunohistochemistry in the detection of human papillomavirus-associated head and neck cancer based on a prospective clinical experience. Cancer 116: 2166-2173.

Smeets SJ, Hesselink AT, Speel EJ, Haesevoets A, Snijders PJ, Pawlita M, Meijer CJ, Braakhuis BJ, Leemans CR, Brakenhoff RH (2007) A novel algorithm for reliable detection of human papillomavirus in paraffin embedded head and neck cancer specimen. Int J Cancer 121: 2465-2472.

Smith SL, Pereira KD (2007) Tonsillectomy in children: indications, diagnosis and complications. ORL J Otorhinolaryngol Relat Spec 69: 336-339.

Weinberger PM, Yu Z, Haffty BG, Kowalski D, Harigopal M, Brandsma J, Sasaki C, Joe J, Camp RL, Rimm DL, Psyrri A (2006) Molecular classification identifies a subset of human papillomavirus-associated oropharyngeal cancers with favorable prognosis. J Clin Oncol 24: 736-747.

Windfuhr JP, Schloendorff G, Baburi D, Kremer B (2008) Serious posttonsillectomy hemorrhage with and without lethal outcome in children and adolescents. Int J Pediatr Otorhinolaryngol 72: 1029-1040.

Windfuhr JP, Schloendorff G, Sesterhenn AM, Prescher A, Kremer B (2009) A devastating outcome after adenoidectomy and tonsillectomy: ideas for improved prevention and management. Otolaryngol Head Neck Surg 140: 191-196.

This work is published under the standard license to publish agreement. After 12 months the work will become freely available and the license terms will switch to a Creative Commons AttributionNonCommercial-Share Alike 4.0 Unported License.

Supplementary Information accompanies this paper on British Journal of Cancer website (http://www.nature.com/bjc) 